\title{
The Research on Development Strategy of Building Engineering Industry
}

\author{
Mei Lu ${ }^{a}$, Haoran Wang ${ }^{b}$ \\ Xi'an University of Architecture \& Technology, Xi'an 710055, China \\ a497894664@qq.com, b2394020588@qq.com
}

Keywords: Building engineering; Project value chain; Extenics.

\begin{abstract}
Building engineering is one of the pillar industries in our country. But it is really competitive so that industrial concentration is low. Industrial restructuring is the most effective way for our country optimize the industrial structure. Firstly, use the theory of entropy and priority degree evaluation method in extenics to build the model of industrial restructuring target selection,; Then, take Shanxi, Sichuan, Beijing and Shanghai as examples, use the data and model to compare the Construction industry development of four provinces with Chinese average level, and we can know which province have to optimize its building engineering industrial structure firstly and how to optimize.
\end{abstract}

\section{Introduction}

Recently, the business of Building engineering occupied a pivotal position in the economic development of the country, but the industrial concentration is low. According to the ENR ${ }^{[1]}$, this paper states the turnover of Chinese engineering contractor from 2007 to 2012, and calculate the number of $\mathrm{CR}_{4}$ and $\mathrm{CR}_{8}$. Listed as table 1

Table1 industrial concentration of Chinese engineering contractor from 2007 to 2012 (Hundred million) $^{[3]}$

\begin{tabular}{ccccccc}
\hline Year & 2007 & 2008 & 2009 & 2010 & 2011 & 2012 \\
Top 4 & 6842.22 & 8248.39 & 11851.31 & 15860.56 & 17225.92 & 18652.96 \\
Top 8 & 9549.20 & 11666.39 & 15479.30 & 20226.87 & 21905.84 & 23784.23 \\
\hline The output value & 51043.71 & 62036.81 & 76807.74 & 96031.13 & 116463.32 & 137217.86 \\
CR $_{4}$ & $13.40 \%$ & $13.30 \%$ & $15.43 \%$ & $16.52 \%$ & $14.79 \%$ & $13.59 \%$ \\
\hline CR $_{8}$ & $18.71 \%$ & $18.81 \%$ & $20.15 \%$ & $21.06 \%$ & $18.81 \%$ & $17.33 \%$ \\
\hline
\end{tabular}

Although the $\mathrm{CR}_{8}$ increased to $20.15 \%$ in 2009 , but it decreased rapidly to $17.33 \%$ in 2012 . The reason which leads to low industry concentration is excessive competition. And the reason of excessive competition is unreasonable industrial structure. So we have to work out the Building engineering development strategy. Therefore, this paper puts forward the point of view that we have to build the model of industrial restructuring target selection, which can help us to work on building engineering development strategy of building engineering industry.

\section{The selection model of industrial restructuring}

The selection of indicators. Lv Wenxue ${ }^{[2]}$ divided the internal competitiveness of construction into five aspects. And the five parts are: technical ability, human resources, the financial capacity, customer relationship management, building engineering industry environment.

The selection of evaluation indexes and quantitative methods, listed as Fig.1:

The selection model of industrial restructuring target selection based on entropy weight and extenics. Determine the measure. According to the information related to space range by evaluation objects and the basis of historical data, determine the accurate measure of the condition set: 
$S I=\left\{S I_{1}, S I_{2}, \ldots, S I_{\mathrm{n}}\right\}, S I_{j}=\left(c_{j}, V_{j}\right)$ are characteristics, $c_{i}$ is evaluation of characteristics, $V_{j}$ are $\left(\mathrm{a}_{j}, b_{j}\right)(\mathrm{j}=1,2, \ldots, \mathrm{n})$.

Determine the coefficient of weight. Calculate the weight coefficient to represent the importance degree of each measure for indicators must meet that based on the entropy weight method, according to important degree respectively, give the value of $[0,1]$

$$
\alpha_{\mathrm{i}}=\left(\alpha_{1}, \alpha_{2}, \ldots, \alpha_{n}\right) \text {, and } \sum_{k=1}^{n} \alpha_{k}=1
$$

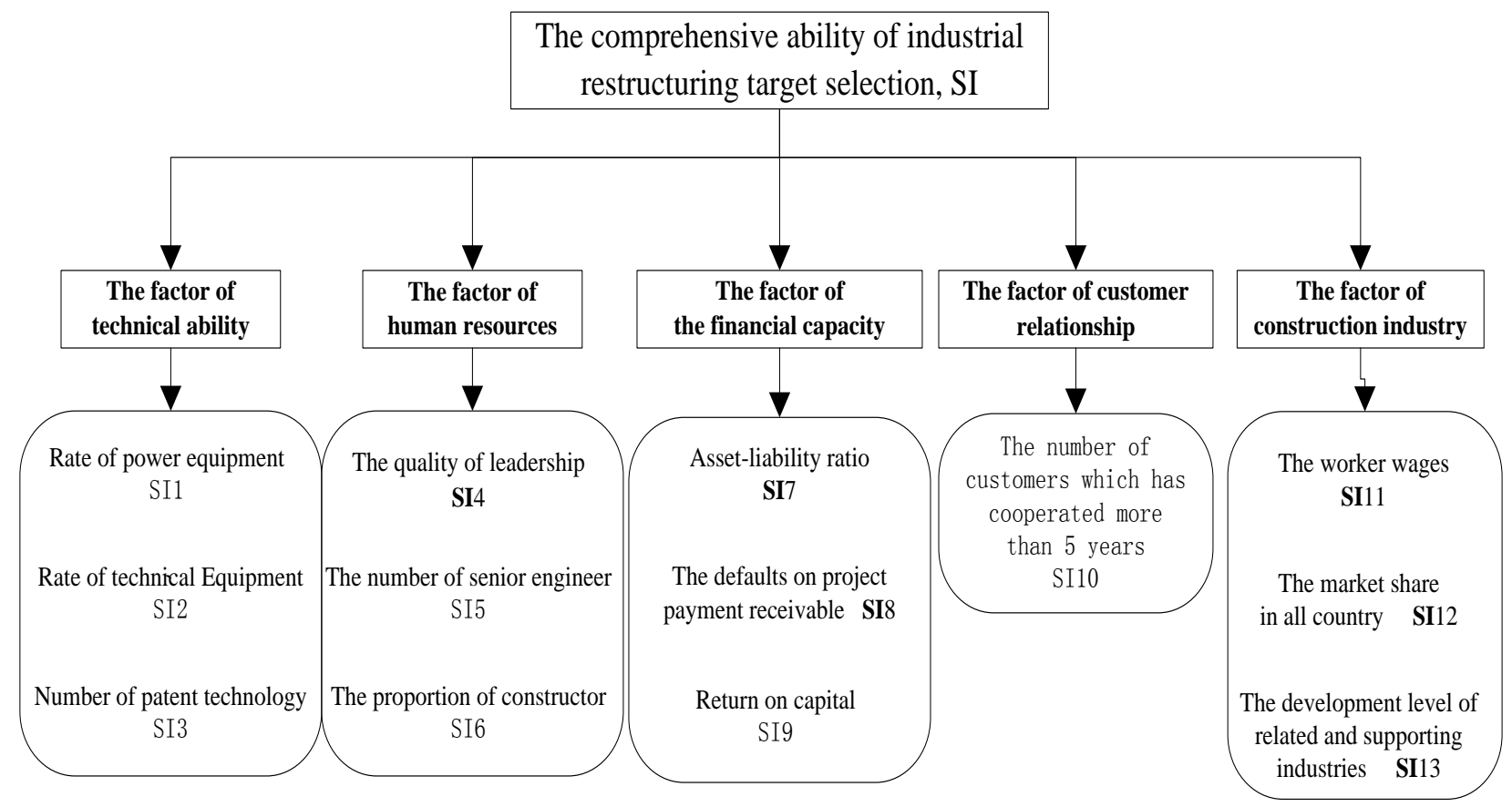

Fig. 1 Industrial restructuring target selection model evaluation index table

Build the correlation functions and calculate correlation. Assuming that $S I=\left\{S I_{1}, S I_{2}, \ldots, S I_{n}\right\}$, $S I_{\mathrm{j}}=\left(c_{j}, V_{j}\right),(i=1,2, \ldots, \mathrm{m}) V_{i}$ is the quantity of quantification domain, $V_{j}=\left(\mathrm{a}_{j}, b_{j}\right)(\mathrm{j}=1,2, \ldots, \mathrm{n})$

Weight distribution as follows: $\alpha_{\mathrm{i}}=\left(\alpha_{1}, \alpha_{2}, \ldots, \alpha_{n}\right)$, and then build the correlation functions . $\mathrm{K}(\mathrm{x})$, Limited range is $\mathrm{V}=[\mathrm{a}, \mathrm{b}], M \in V$

$$
K(x)=\left\{\begin{array}{l}
\frac{x-a}{M-a}, x \leqslant M, \\
\frac{b-x}{b-M}, x \geqslant M,
\end{array}\right.
$$

Make the $Z_{i}$ related with $S I_{j}$ as correlation functions: $K_{j}\left(Z_{i}\right)$, so the correlation objects $Z_{1}, Z_{2}, \ldots, Z_{m}$ about $S I_{j}$ is $\mathrm{K}_{j}=\left(\mathrm{K}_{j}\left(\mathrm{Z}_{1}\right), \mathrm{K}_{j}\left(\mathrm{Z}_{2}\right), \ldots, \mathrm{K}_{j}\left(\mathrm{Z}_{m}\right) \quad j=1,2, \ldots n\right.$.

Make the correlation formally:

$$
k_{i j}=\frac{K_{j}\left(Z_{i}\right)}{\max _{q \in\{1,2, \ldots, m\}}\left|K_{j}\left(z_{q}\right)\right|} \quad i=1,2, \ldots, m ; j=1,2, \ldots n .
$$

So the degree of specification on $\mathrm{Z}_{1}, \mathrm{Z}_{2}, \ldots, \mathrm{Z}_{\mathrm{m}}$ related with $S I_{\mathrm{j}}$ are:

$$
k_{i}=\left(k_{j 1} k_{j 2}, \ldots, k_{j m}\right) \quad j=1,2, \ldots n
$$

Calculate the value. The specification correlation of $Z_{j}$ on $S I_{1}, S I_{2}, \ldots, S I_{n}$ are as follows: 


$$
K\left(Z_{i}\right)=\left[\begin{array}{c}
k_{1 i} \\
k_{2 i} \\
\ldots \\
k_{n i}
\end{array}\right] \quad i=1,2, \ldots, m
$$

According to the actual needs of industrial restructuring target selection model,the value of $Z_{i}$ are calculated as follows:

$$
C\left(Z_{i}\right)=\alpha K\left(Z_{i}\right)=\left(\alpha_{1}, \alpha_{2}, \ldots, \alpha_{n}\right)\left[\begin{array}{c}
k_{1 i} \\
k_{2 i} \\
\ldots \\
k_{n i}
\end{array}\right]=\sum_{i=1}^{n} \alpha_{i} k_{i j}, \quad j=1,2, \ldots, n
$$

Then, compare $\mathrm{C}\left(\mathrm{Z}_{\mathrm{i}}\right),(\mathrm{i}=1,2, \ldots, \mathrm{m})$ with each other.

\section{Example}

The data collection. According to the model. We collect the all data about SI1 SI13 in Shanxi, Sichuan, Beijing and Shanghai through website and questionnaire, we also collect the data about SI1 SI13 in China for comparing, in order to reflect the reality, we split the data into all construction enterprises in average. Then the data of Industrial restructuring target selection model evaluation index table as follow:

\begin{tabular}{|c|c|c|c|c|c|c|c|c|c|c|c|c|c|}
\hline & \multicolumn{3}{|c|}{$\begin{array}{l}\text { technical } \\
\text { ability }\end{array}$} & \multicolumn{3}{|c|}{$\begin{array}{l}\text { human } \\
\text { resources }\end{array}$} & \multirow{2}{*}{$\begin{array}{c}\text { financia } \\
\text { l } \\
\text { capacity } \\
\text { SI7 }\end{array}$} & \multicolumn{3}{|c|}{$\begin{array}{c}\text { customer relationship } \\
\text { management }\end{array}$} & \multicolumn{3}{|c|}{$\begin{array}{c}\text { construction industry } \\
\text { environment }\end{array}$} \\
\hline & SI1 & SI2 & SI3 & SI4 & SI5 & SI6 & & SI8 & SI9 & SI10 & SI11 & SI12 & SI13 \\
\hline unit & $\%$ & $\%$ & $\begin{array}{c}\text { NO } \\
\cdot\end{array}$ & Score & $\begin{array}{c}\text { NO } \\
.\end{array}$ & NO & $\%$ & $\%$ & $\%$ & NO. & $\begin{array}{l}\text { Yuan/ } \\
\text { 1year }\end{array}$ & $\%$ & Score \\
\hline Sichuan & 2.4 & 1.2 & 12 & 85 & 41 & 20 & 61.32 & 68.33 & 11.43 & 8 & 4101 & 1.23 & 80 \\
\hline Beijing & 2.5 & 1.5 & 15 & 90 & 52 & 21 & 52.24 & 58.21 & 14.78 & 17 & 4253 & 2.09 & 95 \\
\hline Shanxi & 1.9 & 1 & 7 & 85 & 43 & 24 & 50.89 & 61.44 & 10.15 & 7 & 3991 & 0.81 & 75 \\
\hline Shanghai & 2.6 & 1.4 & 16 & 80 & 48 & 24 & 57.91 & 51.56 & 16.71 & 12 & 4310 & 1.41 & 85 \\
\hline China & 2.4 & 1.3 & 14 & 85 & 51 & 22 & 55.89 & 66.3 & 12.3 & 14 & 4033 & 1.21 & 85 \\
\hline
\end{tabular}

Table 3 the data of Industrial restructuring target selection model evaluation index table

Calculating the data with model. We assume four provinces are $\mathrm{Z}_{1}, \mathrm{Z}_{2}, \mathrm{Z}_{3}, \mathrm{Z}_{4}$, which are corresponding with Sichuan, Beijing, Shanxi. Shanghai, and $Z_{C}$ are equal with China. Through calculating, the outcomes are:
$C\left(Z_{1}\right)=\alpha_{i} K\left(Z_{1}\right)=0.6474$
$C\left(Z_{2}\right)=\alpha_{i} K\left(Z_{2}\right)=0.9523$
$C\left(Z_{3}\right)=\alpha_{i} K\left(Z_{3}\right)=0.5548$
$C\left(Z_{4}\right)=\alpha_{i} K\left(Z_{4}\right)=0.8042$
$\mathrm{C}\left(Z_{C}\right)=\alpha_{i} K\left(Z_{C}\right)=0.6288$;
$C\left(Z_{2}\right)>C\left(Z_{4}\right)>C\left(Z_{1}\right)>C\left(Z_{\mathrm{c}}\right)>C\left(Z_{3}\right)$;

We can see that $\mathrm{C}\left(\mathrm{Z}_{\mathrm{c}}\right)>\mathrm{C}\left(\mathrm{Z}_{3}\right)$; So, we know that the construction industry development in Shanxi is below the all country's average. And if we want to optimize Chinese construction industrial structure more efficiently, we'd better to improve the construction industry level in Shanxi firstly.

\section{Conclusion}

Through comparing the indicators data in Shanxi with Beijing, Shanghai, Sichuan. We can conclude that Shanxi's unreasonable industrial structure is unreasonable, we have to expand the market in 
Shanxi through the construction of infrastructure and Investment promotion and capital introduction. Also, Shanxi needs to bring more talents and machines in construction industry to promote the technical level. Then, it will promote the construction industry level in Shanxi. And the most important is through the model we established in this paper, we can optimize the construction industrial structure in our country structure more targeted and more efficiently.

\section{Acknowledgments}

Shaanxi Provincial Education Department of Philosophy and Social Science Key Research Base Project. Item Number: 14JZ022. Project Title: Evaluation and Strategy Research on International Competitiveness of the international development of construction enterprises in Shaanxi Province.

\section{References}

[1] Peter Reina,Gary J.Tulacz.The Top 225International Contractors[J].Engineering News-Record, 2007-2012.

[2] Lv Wenxue. A study on the competitiveness of big building enterprises and its upgrading methods [D].Tianjin university,2003.

[3] Yang Huan, Li Qiming. Chinese construction industry concentration degree analysis[J]. Journal of Chongqing Jianzhu University,2008.

[4] Yang Chunyan, Cai Wen. Extension engineering[M].Beijing: Science press.2007.

[5] Li Liyun. The improved entropy method in engineering application research project evaluation scheme selection decisions [D] Tianjin university of finance and economics. 2012. 